\title{
Representation on the Editorial Boards of Academic Psychiatry Journals: the Gender Difference
}

\author{
Monique Mun ${ }^{1}$ (D) Esther Akinyemi ${ }^{1}$
}

Received: 29 April 2020 / Accepted: 7 May 2020 /Published online: 26 May 2020

(C) Academic Psychiatry 2020

To the Editor:

Psychiatry is an increasingly popular specialty among women due to its work-life balance, flexibility of work hours, increasing demand, and opportunities to advance in the field [1]. According to the Association of American Medical Colleges (AAMC), women comprised 39\% of practicing psychiatrists in 2017 compared with $32 \%$ in 2007 [2]. However, it is unknown whether this increase in percentage of female psychiatrists has also translated to more women holding academic leadership roles.

We selected the top twelve psychiatry journals based on a review of impact factor (IF) in 2017 from the article, "the impact factor and psychiatry journals: an international perspective", by Sundararajan Rajagopal, and internet search engines [3]. The twelve psychiatry journals included in the study are: World Psychiatry (30.0000), JAMA Psychiatry (16.6420), The Lancet Psychiatry (15.2330), American Journal of Psychiatry (13.3910), Biological Psychiatry (11.9820), Molecular Psychiatry (11.6400), British Journal of Psychiatry (5.8670), Psychological Medicine (5.4750), Translational Psychiatry (4.6910), European Psychiatry (4.1290), Journal of Psychiatric Research (4.0000), and Psychiatry Research (2.2230). The IF's were verified on the respective journals' websites. Data about the editorial boards were collected from journal websites, LinkedIn, institution profiles, and other professional memberships. Descriptive statistics were used to analyze the data.

Overall, women were under represented in editorial positions. They comprised only $23 \%$ of the total editorial positions across all journals reviewed, with only $17 \%$ of the editor-in-chief positions. Only $27 \%$ of the deputy editor positions and $28 \%$ of the associate editor positions were women. There was no association between journal IF and the prevalence of female editors.

Previously presented at the American Psychiatric Association conference, May 20, 2019, San Francisco, CA.

Monique Mun

Mmun1@hfhs.org

1 Henry Ford Health System, Detroit, MI, USA
This study highlights that there exists a disproportionate presence of female psychiatrists who occupy the roles that most influence future research. Psychiatrists who are on the editorial boards of high-IF psychiatry journals are responsible for overseeing the content that all psychiatrists, even internationally, learn from and refer to. They determine what is published and disseminated and thus, influence the direction of the field. With women approaching almost half of the workforce of practicing psychiatrists, perhaps there should be an equal representation of female psychiatrists on the editorial boards of the most influential psychiatry journals as well. A limitation of the study includes not exploring factors relating to the inequity in the percentage of females in editorial roles. Potential areas for future research include examining factors affecting women in obtaining academic roles, including barriers to applying, lack of mentors or resources, and individual reasons.

\section{Compliance with Ethical Standards}

Conflict of Interest On behalf of all authors, the corresponding author states that there is no conflict of interest.

\section{References}

1. Scottsdale B. Rewards for Being a Psychiatrist [Internet]. Woman. 2016 [cited 2018Dec9]. Available from: https://woman.thenest.com/ rewards-being-psychiatrist-10861.html

2. Data \& Reports - Workforce [Internet]. AAMC. [cited 2018Dec9]. Available from: https://www.aamc.org/data/work force/reports/ 492556/1-1-chart.html

3. Rajagopal S. The impact factor and psychiatry journals: an international perspective: BJPsych International [Internet]. Cambridge Core. Cambridge University Press; 2018 [cited 2018Dec9]. Available from: https://www.cambridge.org/core/journals/bjpsychinternational/article/impact-factor-and-psychiatry-journals-aninternational-perspective/31178151F105C3C334F4FA53C9C24187

Publisher's Note Springer Nature remains neutral with regard to jurisdictional claims in published maps and institutional affiliations. 